\title{
Questionnaire feedback from MBBS second year students about current examination trends and their opinion for perspective changes
}

\author{
Fazeel Zubair Ahmed ${ }^{1}$, Ravi Hanumanthappa Kudthni ${ }^{2 *}$
}

\author{
${ }^{1}$ Department of Pharmacology, Malla Reddy Medical College for Women, Hyderabad, India \\ ${ }^{2}$ Department of Pharmacology, Viswabharathi Medical College, Kurnool, Andhra Pradesh, India
}

\author{
Received: 09 February 2021 \\ Accepted: 05 March 2021 \\ *Correspondence: \\ Dr. Ravi Hanumanthappa Kudthni, \\ Email: docravidr@gmail.com
}

Copyright: (C) the author(s), publisher and licensee Medip Academy. This is an open-access article distributed under the terms of the Creative Commons Attribution Non-Commercial License, which permits unrestricted non-commercial use, distribution, and reproduction in any medium, provided the original work is properly cited.

\begin{abstract}
Background: All subjects of MBBS do not have same examination pattern especially concerning to question paper pattern and distribution of marks. As a result, students are experiencing variety of examination patterns during their study. Neither is their uniformity of examination pattern throughout the country nor there is uniformity within a university. In such situation, it would be wise to take feedback from students which could help in redesigning the examination pattern. This study was done to collect students' opinion regarding current examination methods and possible changes that might be required in existing assessment methods.

Methods: Questionnaire based study was done on MBBS second year students of Viswabharathi medical college. Questionnaire consisted of 10 questions about examinations faced by the students. Each question had five options arranged according to 5-point Likert scale.

Results: 99 students participated in this study. 51.52\% students preferred having two essay questions and $42.42 \%$ preferred having one essay question in final theory exam. $52.53 \%$ preferred to have 40 marks as weightage of one paper. $50.51 \%$ supported having illustration-based questions in their final theory examinations. $79.80 \%$ stated that at least 30 days of preparation holidays are required for them before their final exams. $48.48 \%$ preferred having five very short answer questions. $48.48 \%$ stated that weekend tests conducted by their institute were helpful to them. $66.66 \%$ disagreed upon increasing number of questions in final examination. 63.63\% agreed on having MCQ's. 48.48\% agreed on having viva voce during every internal examination. Consensus could not be reached upon frequency of institutional tests.

Conclusions: This study highlighted certain shortcomings in medical education with respect to examinations. Weightage and number of questions might be increased marginally to have a uniform pattern. Question paper should have more very short answer questions and less essay questions. Illustration based questions should also be introduced. 30 days of preparation holidays must be given before final exams for self-study.
\end{abstract}

Keywords: Feedback, Examination, Medical students, Questionnaire, Opinion, India

\section{INTRODUCTION}

Medical education in India has 15 core subjects. ${ }^{1,2}$ All subjects do not have same examination pattern. ${ }^{1}$ Especially with concern to question paper pattern and distribution of marks. $^{2}$ This difference in examination pattern has been created to considering the weightage of subject and weightage of topics in that subject. In state of Andhra Pradesh, first year MBBS subjects have 2 papers each of
50 marks. But in second year subjects, each paper is for 40 marks. While in third year, they have 40 marks and 60 marks papers. Based on marks weightage the composition of question is also different. ${ }^{2}$ Similarly in state of Karnataka, all papers throughout MBBS are for 100 marks with 2 papers in each subject. Some subjects have 1 paper. ${ }^{3}$ Likewise different universities across India have their own examination pattern. This difference is also seen in practical examinations within university and also across universities. As a result, students are experiencing variety 
of examination patterns during their study. Neither is their uniformity of examination pattern throughout the country nor there is uniformity within a university.

In such situation, it would be wise to take feedback from students which could help in redesigning the curriculum and examination pattern. Opinion of students forms backbone during evaluation of medical education. ${ }^{4}$ Students' feedback would help in making medical education and assessment more enjoyable for them. ${ }^{5,6}$ This study was done to collect students' opinion regarding current examination methods and possible changes that might be required in existing assessment methods.

\section{METHODS}

This was a questionnaire based cross sectional study done in January 2020. Participants were MBBS second year students of Viswabharathi medical college, Kurnool, Andhra Pradesh, India. Prior permission from institutional ethics committee was obtained before initiating the study.

The questionnaire consisted of 10 questions about examinations faced by the students. Opinion was asked about number of questions that should be asked in theory exam in one paper and among those how many should be essay questions, very short answer questions and MCQ's. ${ }^{7}$ Students' opinion was also asked regarding weightage of each paper in theory exam. Further they were asked if they would prefer having diagram or illustration-based questions in theory exam. Our institute conducts a test every weekend in one subject on rotation apart from the internal assessment examination prescribed by university. In this regard students' opinion was asked if weekend tests were helpful to them. Similar to our institute, other medical colleges also conduct tests on routine basis apart from internal assessment. In this regard, students were asked as to how frequently they would prefer to write these institutional tests. Certain universities have given direction to conduct viva voce during every internal assessment, but some universities have focused only on theory. In this regard students were asked whether they would like to have viva voce exam during every internal assessment. Finally considering the exam stress on every student, opinion was asked about how many days of preparation holidays should be given before final exam. Each question had five options arranged according to 5-point Likert scale. ${ }^{8}$ Some questions (e.g.: inclusion of MCQ's in exam) had options arranged as 'strongly agree' to 'strongly disagree'. While few questions (e.g.: number of questions in exam) had range of numbers, students were told to select the appropriate number according to the question.

Students were explained about the purpose of study and written consent was obtained prior to administering questionnaire. They were told not to write their identification details on questionnaire. Students not willing to participate and incomplete responses were excluded from the study.

\section{Statistical analysis}

The number of responses for each option of every question were counted and data was entered into excel spreadsheet. These numbers were converted into percentages so as to know how many percent of the participated population selected a particular option for a given question.

\section{RESULTS}

A total 100 students participated in this study. Out of 100 questionnaires, one was rejected as it was incomplete. Wide variation of preferences was seen among students. Of the 10 questions, students unanimously agreed on one option for six questions. Three questions were such that they received highest number of responses for one option but only $30-40 \%$ students agreed on that option. While on question did not get a common consensus.

A total $51.52 \%$ students preferred having two essay questions and $42.42 \%$ students preferred having one essay question in final theory exam (Figure 1). 52.53\% preferred to have 40 marks as weightage of one paper (Figure 2. $50.51 \%$ students supported having illustration-based questions in their final theory examinations (Figure 3). $79.80 \%$ students stated that at least 30 days of preparation holidays are required for them before their final exams (Figure 4). 48.48\% students preferred having five very short answer questions (Figure 5). 48.48\% students stated that weekend tests conducted by their institute were helpful to them (Figure 6).

Majority students unanimously disagreed upon increasing number of questions in final examination, $33.33 \%$ disagreed and $33.33 \%$ strongly disagreed to this (Figure 7). Regarding having MCQ's in theory examination, 36.36\% agreed and $27.27 \%$ strongly agreed in having MCQ's (Figure 8). Their opinion about conducting viva voce during every internal examination drew support by $39.39 \%$ students agreeing and $9.09 \%$ students strongly agreeing to it (Figure 9).

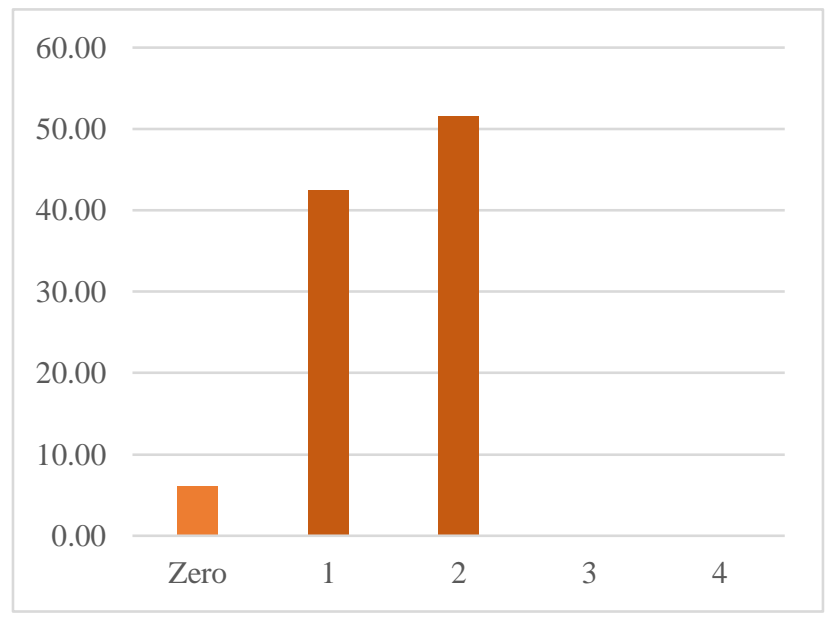

Figure 1: In your opinion, how many essay questions (10 marks) should be asked in final exam? 


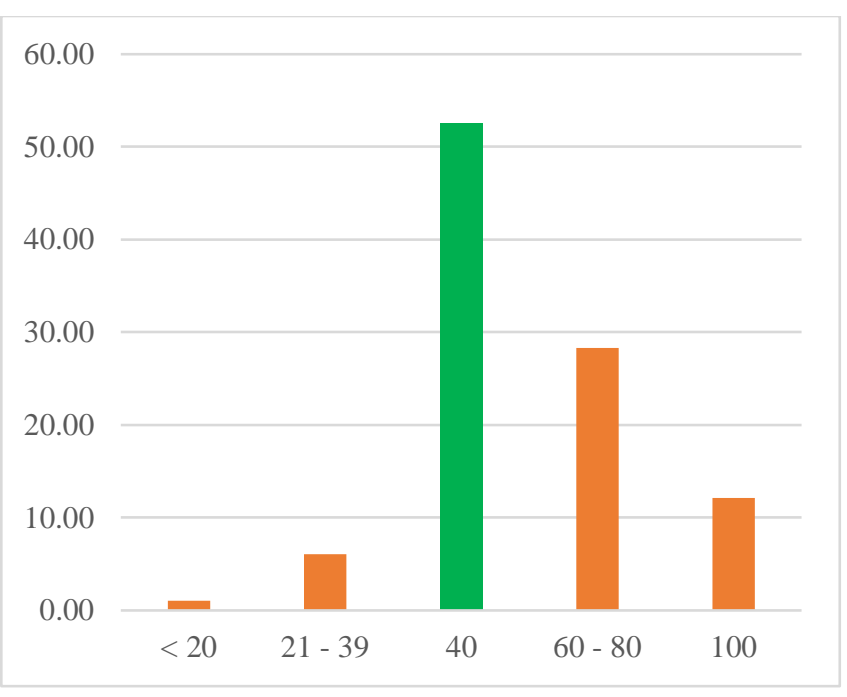

Figure 2: In your opinion, how much should be the maximum marks for each paper in final exam?

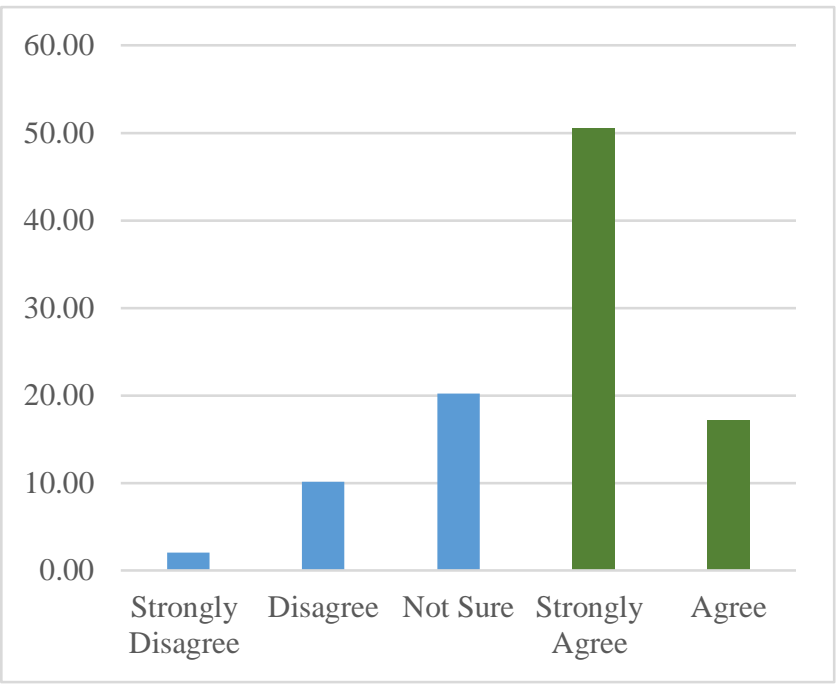

Figure 3: Do you think diagram/figure-based questions should be included in final theory exam?

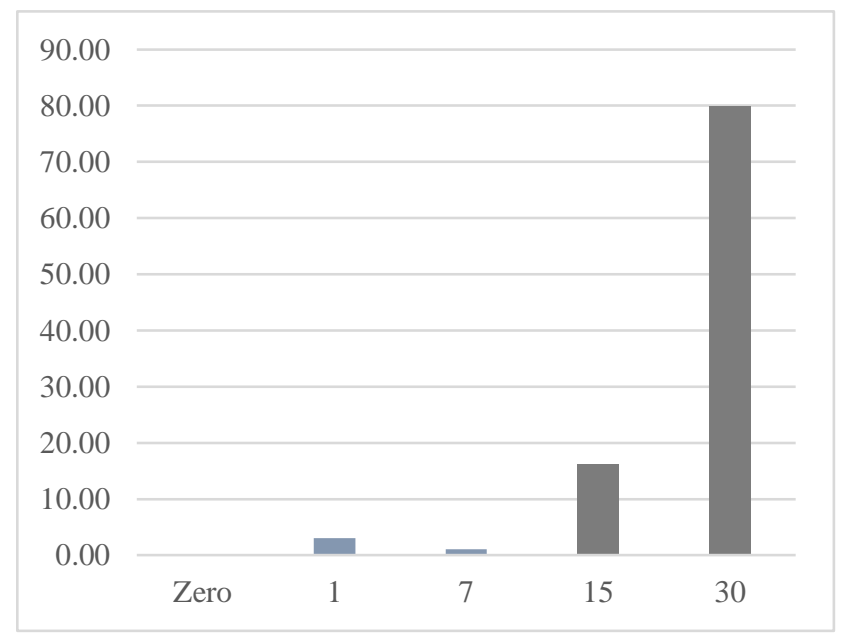

Figure 4: In your opinion, how many days of holidays should be given for final exam preparation?

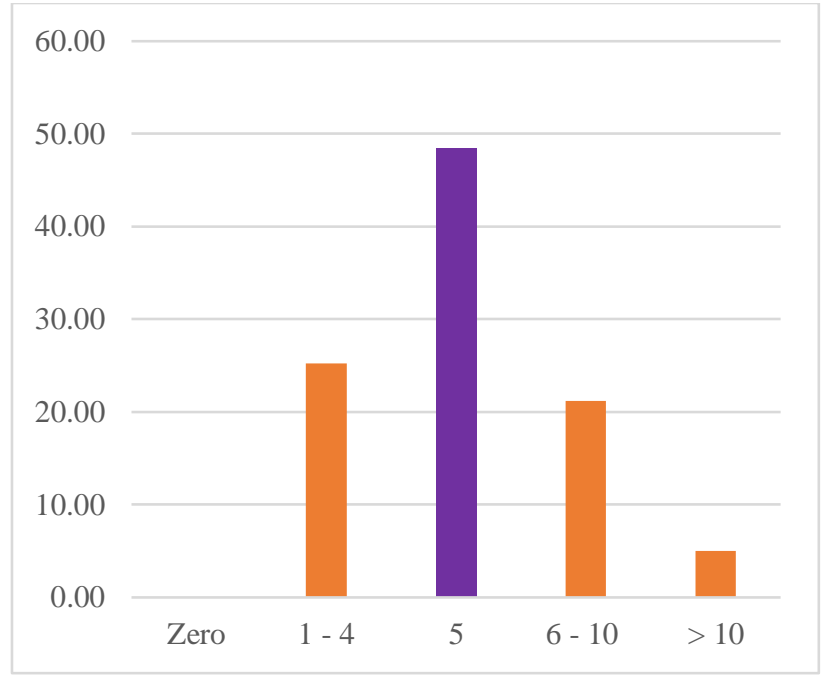

Figure 5: In your opinion, how many very short questions ( 2 marks) should be asked in final exam?

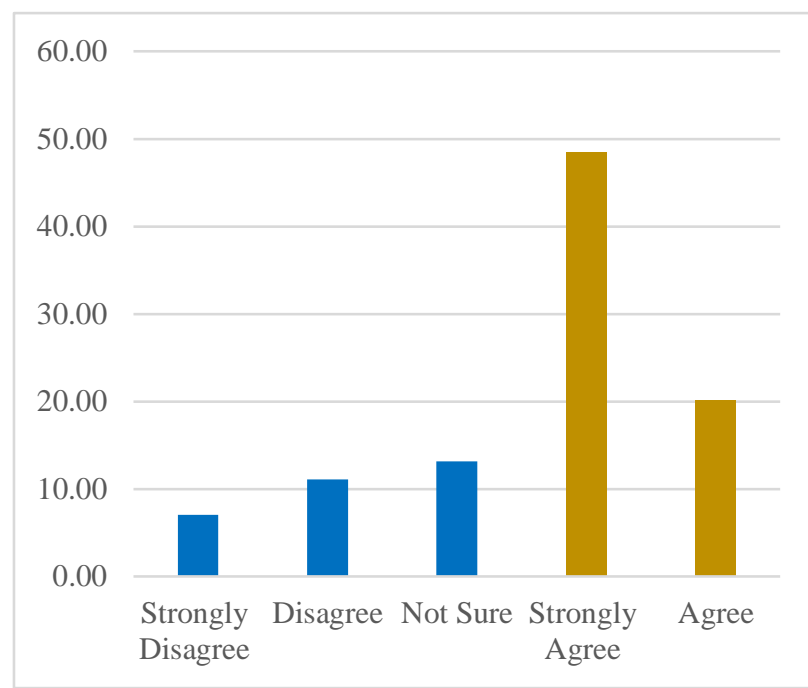

Figure 6: Are the weekend tests which are conducted by the college helpful to you?

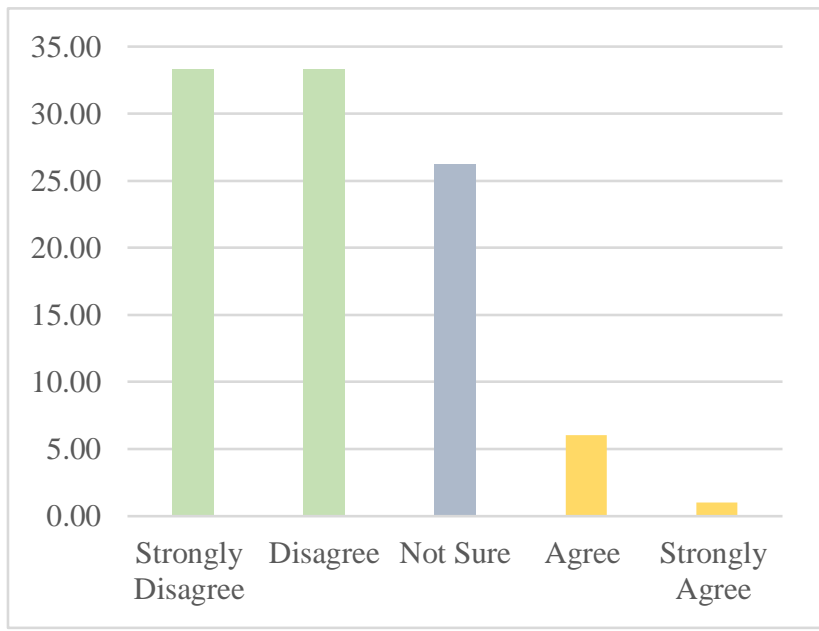

Figure 7: Do you think number of questions in final theory examination should be increased? 


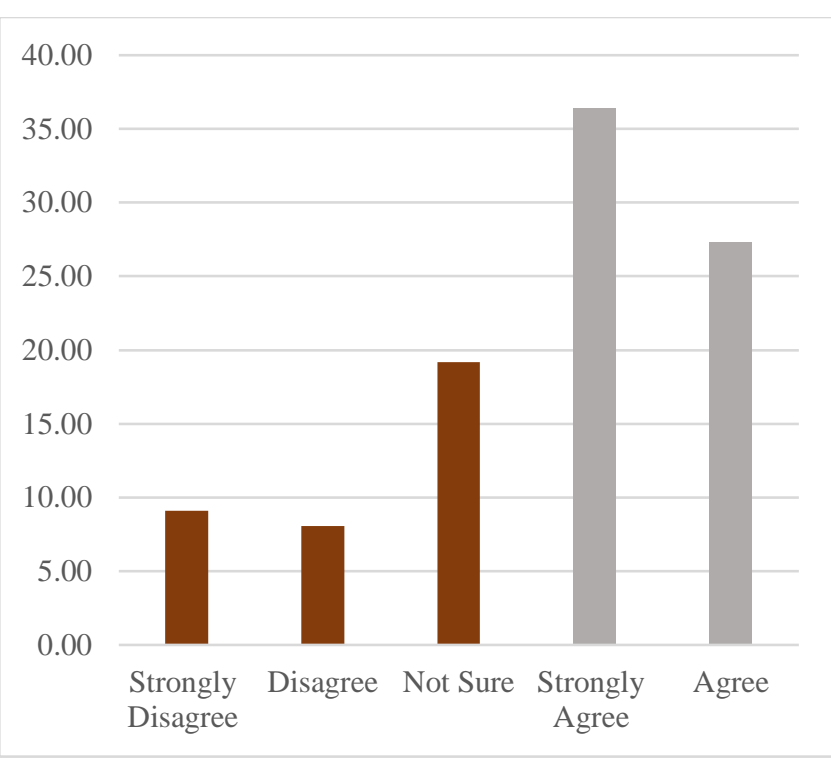

Figure 8: Do you think viva voce should be conducted along with every internal assessment?

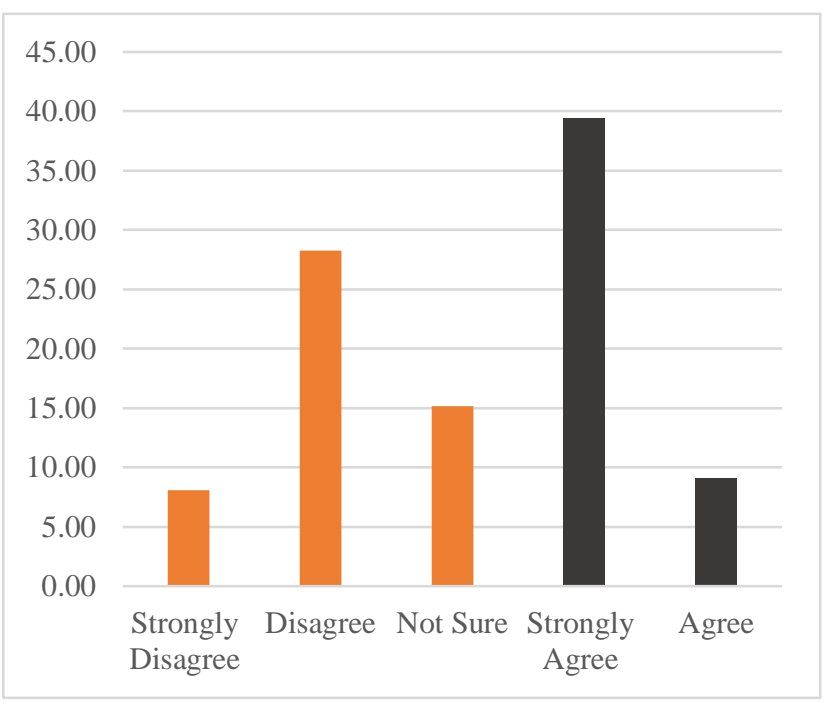

Figure 9: Do you think viva voce should be conducted along with every internal assessment?

Consensus could not be reached upon frequency of institutional tests apart from internal assessment. $28.28 \%$ preferred having them twice in a year, $22.22 \%$ preferred having monthly tests and few students had also preferred for four monthly and weekly tests.

\section{DISCUSSION}

This study was conducted to allow students to express their honest thoughts anonymously and also to identify the areas of improvement pertaining to examination. Another objective of this study was to outline the need and scope for innovation in certain areas. Assessment pattern is one of the factors for a student's interest in a particular subject. It is the responsibility of the curriculum designers to modify examination patterns such that it attracts more interest of students. Justification of an assessment method mostly depends on true opinion of the students. ${ }^{9}$ However, it is not easy to ensure genuineness of a student's opinion. Although most participants gave consistent responses, few have given responses far away from the general consensus. This could be due to either lack of interest, unpreparedness or may be because they desired drastic changes in curriculum.

A total $66.66 \%$ students unanimously disagreed for increasing number of questions. $26.26 \%$ were not sure about it. However, this was the first question asked to them and only in later questions it was specified about type of questions. Majority students in our study were not keen on increasing number of essay questions. They $(51.52 \%)$ were satisfied with having two essay questions in one paper. Nearly half $(42.42 \%)$ of the participants preferred having only one essay question. There were $6.06 \%$ students who opined that there should not be any essay question. It is important to note that no student supported having more than 2 essay questions. Current exam pattern has five very short answer questions and nearly half of the class $(48.48 \%)$ supported in continuing the same. However, $25.25 \%$ students were in favour of reducing them to less than five and $21.21 \%$ were in favour of increasing them to more than 5 but less than 10. $5.05 \%$ students did support increasing them to more than 10 . This tells us that question paper should focus on having a greater number of questions where required length of answers should be short. So that variety of questions can be asked assessing the extent instead of assessing depth.

A total $63.63 \%$ students were in favour having MCQ's in theory question paper. $17.17 \%$ were against having MCQ's. 19.19\% were not sure about having MCQ's. Having MCQ's may help students prepare for entrance exams like NEET but in such case the questions too should of NEET standard. Otherwise, it is often observed that MCQ's become a major area of malpractice during examination.

Present examination pattern in second year MBBS has question papers of 40 marks each. When our participants were in first year MBBS they have seen 50 marks question paper. By comparing both years, $52.53 \%$ students preferred in having 40 marks question paper. $28.28 \%$ students supported that weightage should be increased to range of 60-80 marks. $12.12 \%$ students favored having 100 marks paper. These numbers appear biased because these students have not experienced 100 marks weightage question papers seen in other universities. Hence, they may not decide on pros and cons of increasing weightage.

A total $67.68 \%$ were in favors of having illustration-based questions in exams. $20.20 \%$ were not sure about having this while $12.12 \%$ were against having illustration-based question. This tells us that student are supporting towards having a major change curriculum and assessment. If questions are asked to them based on an X-ray image or 
ECG, then it will modify the curriculum in learning more practical aspects from initial stage.

A total $68.68 \%$ students agreed that weekend tests are helpful to them while $18.18 \%$ were against having weekend tests and $13.13 \%$ were not sure. However, consensus could not be reached on frequency of such tests. As of now it was apparent that regular tests are required by students to keep them motivated for studying and also to instill practice of writing exams but frequency should not be too much that they become tolerant to examinations and ignore final examination.

Nearly half of the class were in favour of having viva voce examination along with written theory internal examination. This will help in better evaluation of a student. Certain aspects not covered in written exam are covered in oral exam. Hence students should not face viva voce directly in final exam but also during internal assessments too. This point is also supported by Gharibyan et al that written exams do not always give correct assessment of knowledge of student. ${ }^{10}$

Lastly, judging from unanimous response of students about having preparation holidays for 30 days, it is apt that they need sufficient time for self-study. Hence syllabus must be completed a month before commencement of exams and students must be given ample time for themselves to study. Forcing them to attend classes or writing tests will only be hazardous for their last moment exam preparation.

We could not find any questionnaire study which has asked similar questions hence could not compare our results.

\section{CONCLUSION}

This study has highlighted certain shortcomings in medical education with respect to examinations. Weightage and number of questions might be increased marginally to have a uniform pattern throughout MBBS. Question paper should have more very short answer questions and lesser essay questions so as to assess the extent of subject. Illustration based questions can also be introduced in MBBS which are currently asked in NEET. Self-study is very important for a student hence 30 days of preparation holidays must be given before final exams during which students must not be forced to come for any academic activity.

These modifications should be addressed by concerned authorities. While certain existing aspects are welcomed by students but proper consensus was not reached in certain aspects. Performing this study among different batches of different colleges will provide better representation of students' opinion.
Funding: No funding sources

Conflict of interest: None declared

Ethical approval: The study was approved by the Institutional Ethics Committee

\section{REFERENCES}

1. All India Institute of Medical Sciences. Syllabus MBBS at the AIIMS. New Delhi. 2005.

2. NTR university of health sciences. Hand Book for Students MBBS course regulations. Vijayawada.

3. Rajiv Gandhi university of health sciences. Revised Ordinance Governing MBBS degree course and curriculum. Bangalore; 2009. Available from: https://www.rguhs.ac.in/courses_rguhs/medical_ordi nances/MBBS\%20DEGREE\%20COURSE\% 20$\% 20 I \% 20-\% 20$ II-\%202004.pdf. Accessed on 24 August 2020.

4. Sai NP. Comprehensive analysis of theory exam question papers of 2nd MBBS Pharmacology subject in Rajiv Gandhi University of Health Sciences, Karnataka, India. Int J Basic Clin Pharmacol. 2019;8(8):1793.

5. Preston R, Gratani M, Owens K, Roche P, Zimanyi M, Malau-Aduli B. Exploring the Impact of Assessment on Medical Students' Learning. Assess Eval High Educ. 2020;45(1):109-24

6. Jamshidian S, Haghani F, Yamani N, Sabri MR. Provision of feedback to medical teachers on their educational performance: perspectives of internal medicine teachers. Adv Med Educ Pract. 2019;10:85-94.

7. Herrero JI, Lucena F, Quiroga J. Randomized study showing the benefit of medical study writing multiple choice questions on their learning. BMC Med Educ. 2019;19(1):42.

8. Preedy VR, Watson RR. 5-Point Likert Scale. In: Handbook of Disease Burdens and Quality of Life Measures. New York, NY: Springer New York. 2010;4288-8.

9. Sharma SC, Maharjan S. Entry knowledge and situational feedback of MBBS students. Kathmandu Univ Med J. 2005;3(4):442-8.

10. Gharibyan H. Assessing students' knowledge: oral exams vs. written tests. ACM SIGCSE Bull. 2005;37(3):143.

Cite this article as: Ahmed FZ, Kudthni RH. Questionnaire feedback from MBBS second year students about current examination trends and their opinion for perspective changes. Int J Basic Clin Pharmacol 2021;10:483-7. 